\title{
An Analytical Comparison of Dako 28-8 PharmDx Assay and an E1L3N Laboratory-Developed Test in the Immunohistochemical Detection of Programmed Death-Ligand 1
}

\author{
John Cogswell ${ }^{1} \cdot$ H. David Inzunza ${ }^{1} \cdot$ Qiuyan $\mathrm{Wu}^{1} \cdot$ John N. Feder ${ }^{1}$. \\ Gabe Mintier $^{1} \cdot$ James Novotny $^{1} \cdot$ Diana M. Cardona $^{2}$
}

Published online: 26 September 2016

(c) The Author(s) 2016. This article is published with open access at Springerlink.com

\begin{abstract}
Aim Nivolumab, a fully human immunoglobulin G4 programmed death-1 (PD-1) immune checkpoint inhibitor antibody, has activity in melanoma, non-small-cell lung cancer (NSCLC), renal cell carcinoma (RCC), and Hodgkin lymphoma. Nivolumab is approved in the USA and EU for advanced melanoma, NSCLC, and RCC, and relapsed Hodgkin lymphoma in the USA. Programmed death-ligand 1 (PD-L1), a PD-1 ligand, is expressed on mononuclear leukocytes, myeloid cells, and tumor cells. PD-L1 is being investigated as a potential biomarker to predict the association of tumor PD-L1 expression with nivolumab efficacy.

Methods Bristol-Myers Squibb and Dako previously reported on an automated PD-L1 immunohistochemical (IHC) assay that detects cell surface PD-L1 in formalinfixed, paraffin-embedded, human tumor tissue specimens using Dako's Autostainer Link 48. The primary antibody for this assay is a rabbit monoclonal antihuman PD-L1 antibody, clone 28-8. Another rabbit monoclonal antihuman PD-L1 antibody, clone E1L3N, was compared with
\end{abstract}

Electronic supplementary material The online version of this article (doi:10.1007/s40291-016-0237-9) contains supplementary material, which is available to authorized users.

John Cogswell

john.cogswell@bms.com

1 Clinical Histochemistry, Clinical Translational Technologies \& Operations, Bristol-Myers Squibb Company, LVLH4.427B, Route 206 and Province Line Rd, Princeton, NJ 08543, USA

2 Duke University Medical Center, Durham, NC, USA
28-8 for specificity and sensitivity using an identical detection method followed by vendor-recommended detection methods.

Results Using PD-L1 null clones of L2987 and ES-2 tumor cell lines, both antibodies were specific for detection of PD-L1 on the plasma membrane, although E1L3N also stained cytoplasm in ES-2 knockout cells. Using the identical method, E1L3N was slightly more sensitive than 28-8 based on staining intensities. Using manufacturerrecommended detection methods and predefined scoring criteria for plasma membrane staining of tumor and immune cells, 28-8 demonstrated significantly improved detection compared with E1L3N.

Conclusions Epitope retrieval and highly sensitive detection reagents are key determinants in IHC detection of PD-L1.

\section{Key Points}

Rabbit monoclonal anti-programmed death-ligand 1 (anti-PD-L1) antibodies clone 28-8 and E1L3N both demonstrated PD-L1 target specificity (E1L3N, only at the plasma membrane).

Sensitivity of the two antibodies was comparable when an identical immunohistochemical retrieval and detection method was used; however, detection significantly improved with 28-8 versus E1L3N using manufacturer-recommended methods specific for each antibody.

Epitope retrieval and sensitive detective reagents are important for achieving optimal target specificity and sensitivity. 


\section{Introduction}

Nivolumab, a fully human immunoglobulin (Ig) G4 programmed death-1 (PD-1) immune checkpoint inhibitor antibody, is approved in the USA for unresectable or metastatic melanoma alone or in combination with ipilimumab, advanced renal cell carcinoma (RCC) after prior antiangiogenic therapy, metastatic non-small-cell lung cancer (NSCLC) after progression on or after platinumbased chemotherapy, and relapsed or progressive classical Hodgkin lymphoma following autologous hematopoietic stem cell transplantation and brentuximab vedotin [1]. It is approved in the EU for unresectable or metastatic melanoma alone or in combination with ipilimumab, advanced RCC after prior therapy, and locally advanced or metastatic NSCLC after prior chemotherapy [2]. PD-1 and its ligands are checkpoint regulators in immune cells [3-6]. Programmed death-ligand 1 (PD-L1), one of the two PD-1 ligands, can also be expressed on the surface of tumor cells as a potential mechanism to engage PD-1 on the surface of the effector immune cells and evade an antitumor immune response [7-10]. The expression of PD-L1 has been reported on tumor cells in NSCLC and melanoma, among other tumor types [10-16]. Immunoassays employing different primary antibodies, assay formats, and scoring approaches to assess the prevalence of positive PD-L1 expression in NSCLC, melanoma, and RCC have been reported [7, 8, 10, 16-18], although few of these reports have directly compared the impact of antibody specificity and detection sensitivity [18]. Studies have shown that antibodies developed against PD-L1 show variable ability to detect PD-L1 in the cell plasma membrane compartment compared with the cytoplasm compartment $[19,20]$. Some antibodies may not even be wholly specific for PD-L1 [18]. In the present study, we compare the specificity and sensitivity of the antibodies clone $28-8$ and clone E1L3N, to evaluate the performance of the validated Bristol-Myers Squibb (BMS) and Dako assay (PD-L1 IHC 28-8 pharmDx) and the Cell Signaling Technology (CST) assay. The PD-L1 IHC 28-8 pharmDx assay is approved by the US Food and Drug Administration (FDA) as a complementary diagnostic for non-squamous NSCLC and melanoma in the USA and CE marked in the EU.

\section{Materials and Methods}

\subsection{Generation of Antibodies 28-8 and E1L3N, Tumor Cell Lines and Tumor Samples}

The rabbit monoclonal antihuman PD-L1 antibody 28-8 was produced by Abcam (lot \#3), and the rabbit monoclonal antihuman PD-L1 antibody E1L3N by CST. Commercial tissue samples as well as L2987 and ES-2 parent cell lines and their respective knockout cell lines, L2-14 and T1-11, were used for specificity testing. Inframe translation stop codons in L2987 and ES-2 cells were introduced via genetic editing to create clones of L2987 and ES-2 that were null of PD-L1. A transcription activator-like effector nuclease (TALEN) genomic targeting approach was employed. A TALEN pair that recognizes a sequence common to all expressed isoforms within the fourth exon of the PD-L1 gene $(C d 274)$ was designed and constructed at Cellectis (Paris, France) [21]. Tonsil and squamous head and neck carcinoma samples were used for sensitivity testing. Tonsil, NSCLC, and squamous head and neck carcinoma specimens were from Asterand Biosciences (Detroit, Michigan), and melanoma specimens were from MT Group (Van Nuys, California).

\subsection{Immunohistochemical Procedures}

In the first testing procedure, specimens were epitope retrieved and tested using an identical BMS-developed procedure (see the electronic supplementary material, Supplemental Table 1a). Briefly, the specimen slides were de-paraffinized and rehydrated as follows: xylene, $2 \times 5 \mathrm{~min} ; 100 \%$ ethanol, $2 \times 2 \mathrm{~min} ; 95 \%$ ethanol, $2 \times 2 \mathrm{~min} ; 70 \%$ ethanol, $2 \times 2 \mathrm{~min}$; distilled water, $1 \times 2 \mathrm{~min}$. The antigen retrieval process was performed with the Target Retrieval Solution ( $\mathrm{pH}$ 6.0, Dako) at $110{ }^{\circ} \mathrm{C}$ for $10 \mathrm{~min}$ in the Decloaking Chamber (Biocare Medical). Slides were then stained with the Novolink Polymer kit (Leica Biosystems) on the BioGenex i6000 autostainer. Visual assessments were conducted with photographs of the same region on serial sections. E1L3N was sourced from CST, while 28-8 was from a lot manufactured by Abcam for BMS. A negative control rabbit IgG was used and did not show any staining (data not shown).

In the second testing procedure, each antibody was assessed using the manufacturer-recommended detection methods on test commercial clinical samples. The 28-8 antibody was tested using Dako PD-L1 IHC 28-8 pharmDx (Dako North America; SK005) and the Dako-recommended protocol, as previously described [21]. For the PDL1 IHC 28-8 pharmDx assay, tumor tissue sections were de-paraffinized and antigen-retrieved at $97{ }^{\circ} \mathrm{C}$ for $20 \mathrm{~min}$ in the PT Link. Detection of PD-L1 protein was conducted using $2 \mu \mathrm{g} / \mathrm{mL}$ of the antibody on the Autostainer Link 48 according to Dako instructions (Supplemental Table 1a).

The E1L3N antibody was tested using the CST-recommended protocol, as previously described (CST \#13684 PD-L1 E1L3N XP Rabbit mAb Technical sheet). For 
Fig. 1 Target retrieval is better at b $110{ }^{\circ} \mathrm{C}$ for $10 \mathrm{~min}$ compared with a $97{ }^{\circ} \mathrm{C}$ for $20 \mathrm{~min}$ in the melanoma 028-MT0261-61 sample

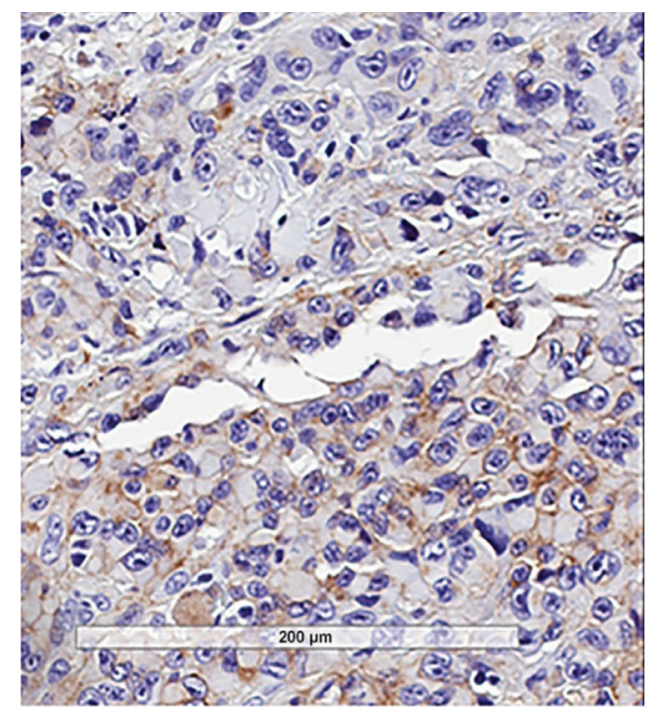

E1L3N, $97^{\circ} \mathrm{C} 20$ minutes

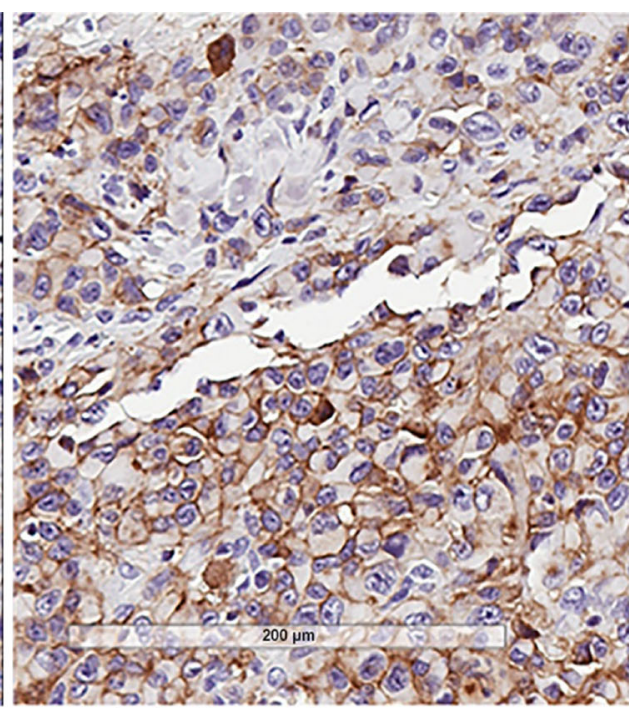

E1L3N, $110^{\circ} \mathrm{C} 10$ minutes
E1L3N, the manufacturer did not specify a heat-induced epitope retrieval (HIER) condition; therefore, samples were tested at $110{ }^{\circ} \mathrm{C}$ for $10 \mathrm{~min}$ and $97{ }^{\circ} \mathrm{C}$ for $20 \mathrm{~min}$. Because $110{ }^{\circ} \mathrm{C}$ for $10 \mathrm{~min}$ (the original condition used in specificity tests) showed improved sensitivity over $97{ }^{\circ} \mathrm{C}$ for $20 \mathrm{~min}$, this condition was retained for E1L3N (Fig. 1a, b). Immunohistochemistry (IHC) was conducted according to manufacturer specifications using $3.5 \mu \mathrm{g} / \mathrm{mL}$ of the antibody with the CST-recommended SignalStain detection kit (Supplemental Table 1a).

\subsection{Analysis}

The sensitivity of each manufacturer's protocol was evaluated by linear cell surface staining of tumor and immune cells, including both circumferential and noncircumferential staining. Tumor PD-L1 expression was evaluated using the histoscore method, and pathologists were encouraged to score in $1 \%$ increments in the $1-10 \%$ range. PD-L1 expression on immune cells was evaluated by its frequency and scored as absent (0), rare (1), moderate (2), or intense/diffuse (3). A single trained pathologist (DMC) was blind to the identity of the antibodies and protocols. The antibodies were evaluated in sequence, with a 1-month washout period between evaluations. In addition, two independent trained pathologists (JS and MB) evaluated each stain separately and then convened to compare significant differences. A comparison of the manufacturer-recommended protocols reveals differences among the protocols, including a higher concentration of the E1L3N antibody and different reagents in each detection kit (Supplemental Table 1a, b).

\section{Results}

\subsection{Target Specificity Using Identical Detection Conditions}

To test the specificity of the E1L3N antibody for PD-L1, genetic deletion of PD-L1 [21] was tested on L2987 and ES-2 cells using a HIER and detection condition that was optimal for both antibodies (see Sect. 2). Rabbit monoclonal antibody (mAb) $28-8$ is specific for its human PDL1 target in L2987 (Fig. 2a-d) and ES-2 cells (Fig. 2e-h). This is evidenced by the loss of cell surface staining in cells where the expression of PD-L1 has been eliminated by a TALEN-induced double-stranded break within the fourth exon of the gene and the subsequent creation of an in-frame translational stop codon by the repair process of non-homologous end jointing (NHEJ). E1L3N stains the plasma membrane of parental L2987 and ES-2 cells, but not in cells null for PD-L1 expression. However, detection of cytoplasmic staining remained in $5 \%$ of PD-L1 null ES-2 cells (Fig. 2h). These experiments demonstrate that 28-8 and E1L3N are specific for cell surface PD-L1, but that E1L3N may also recognize another unrelated, non-PD-L1 antigen within the cytoplasm. Cytoplasm staining in tissues not expected to express PD-L1 has been seen by others, albeit at much higher concentrations of E1L3N than was used in this study [22].

\subsection{Sensitivity Using Identical Detection Conditions}

E1L3N was compared with 28-8 using the same protocol to allow evaluation under identical detection conditions. Both antibodies were tested on chronic tonsillitis and squamous 
Fig. 2 a-d Intrinsic specificity of L2987 and KO cell lines: both E1L3N and 28-8 appear to be specific to PD-L1, as all staining is completely eliminated in the L2987 KO cell line. Both 28-8 and E1L3N were tested at $2 \mu \mathrm{g} / \mathrm{mL}$. e-h Intrinsic specificity of ES-2 and KO cell line: both E1L3N and 28-8 appear to be specific to PD-L1, as all plasma membrane staining is eliminated in the $\mathrm{L} 2987 \mathrm{KO}$ cell line; however, some cytoplasm staining remains with E1L3N. 28-8 concentration was increased to $3 \mu \mathrm{g} / \mathrm{mL}$ so staining intensity was equivalent to E1L3N at $2 \mu \mathrm{g} /$ $\mathrm{mL}$. $A b$ antibody, $K O$ knockout, $P D$-L1 programmed deathligand 1

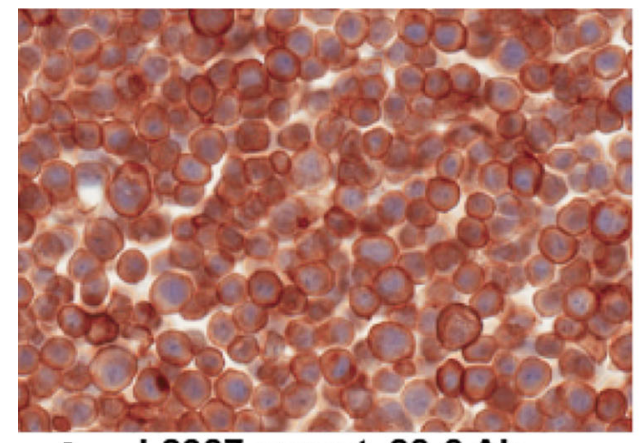

\section{A L2987 parent, 28-8 Ab}

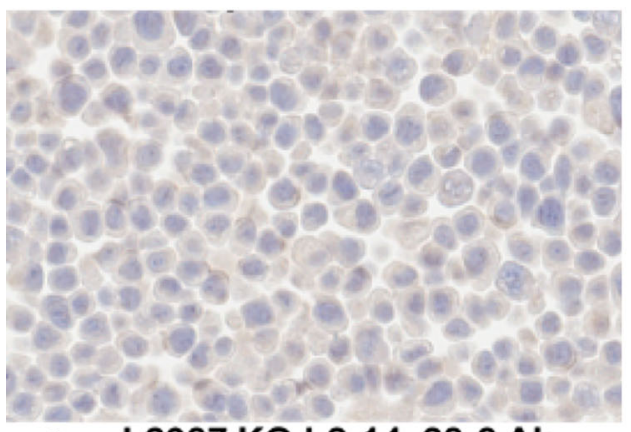

\section{L2987 KO L2-14, 28-8 Ab}

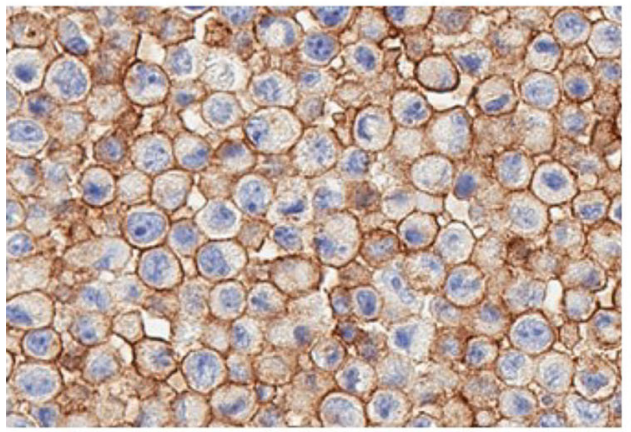

E ES-2 Parent, 28-8 Ab $3 \mu \mathrm{g} / \mathrm{mL}$

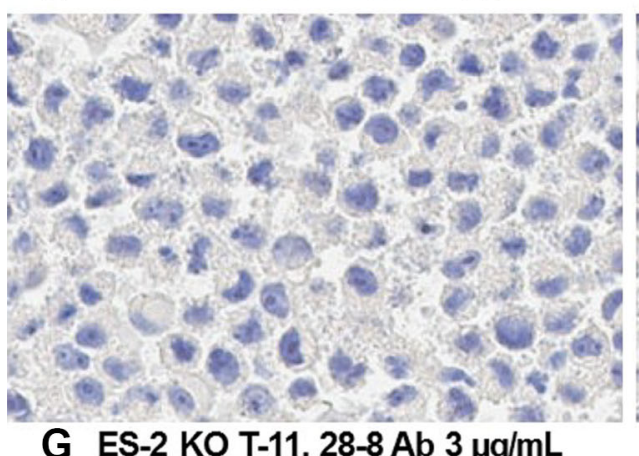

G ES-2 KO T-11, 28-8 Ab $3 \mu \mathrm{g} / \mathrm{mL}$

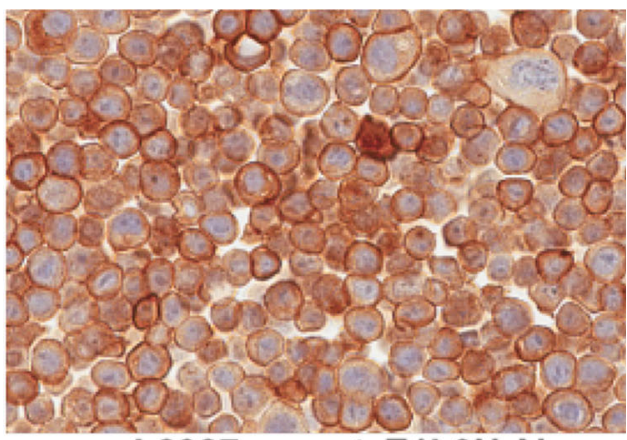

B L2987 parent, E1L3N Ab

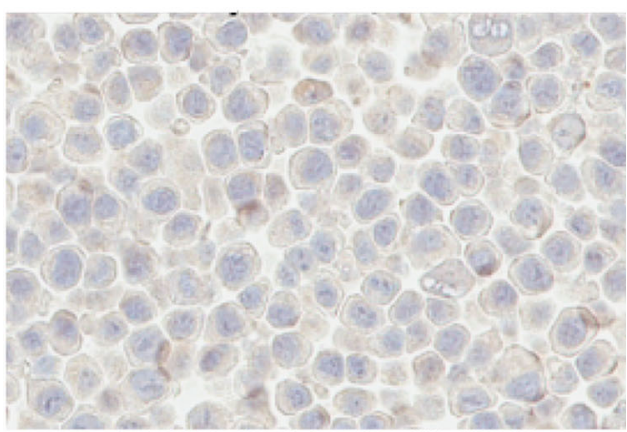

D L2987 KO L2-14, E1L3N Ab

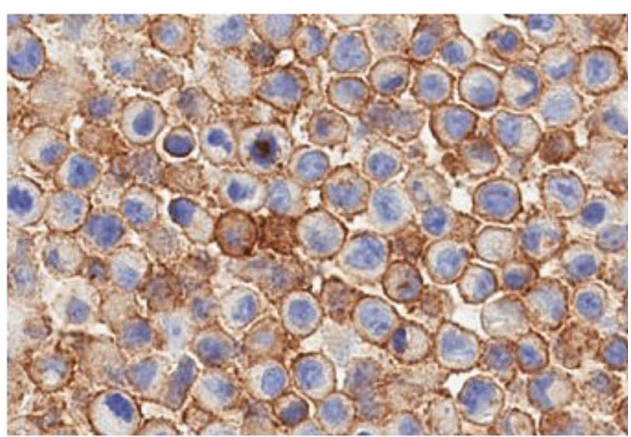

F ES-2 Parent, E1L3N Ab $2 \mu \mathrm{g} / \mathrm{mL}$

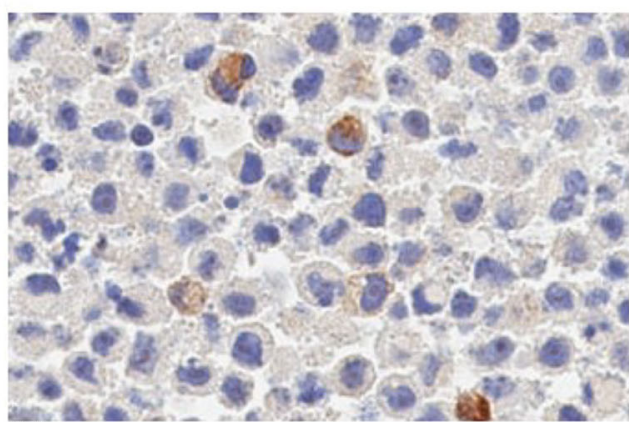

H ES-2 KO T1-11, E1L3N Ab $2 \mu \mathrm{g} / \mathrm{mL}$ head and neck carcinoma samples. In the tonsil samples, both antibodies stained follicular and interfollicular mononuclear cells as well as crypt epithelium spindloid cells, which resemble macrophages and dendritic cells. Both antibodies also stained the plasma membrane of the squamous head and neck tumor. Staining was similar for both antibodies, although E1L3N stained $40 \%$ of tumor cells (vs. $25 \%$ with 28-8) and exhibited slightly higher intensities for cells of both epithelial (Fig. 3a-d) and immune cell origin (Fig. 3e, f). 
Fig. 3 Intrinsic sensitivity. a, b Staining of head and neck tumor cells is slightly higher with E1L3N compared with 28-8, although overall intensity does not shift out of $1+$ intensity. c, d Staining intensity of tonsil crypt epithelium was slightly higher with E1L3N relative to 28-8. e, f E1L3N has slightly greater intrinsic sensitivity on lymphoid and spindloid cells. PD-L1 expression in tingible body macrophages homing the germinal centers in secondary follicles is similar between $28-8$ and E1L3N. $A b$ antibody, $P D$ $L 1$ programmed death-ligand
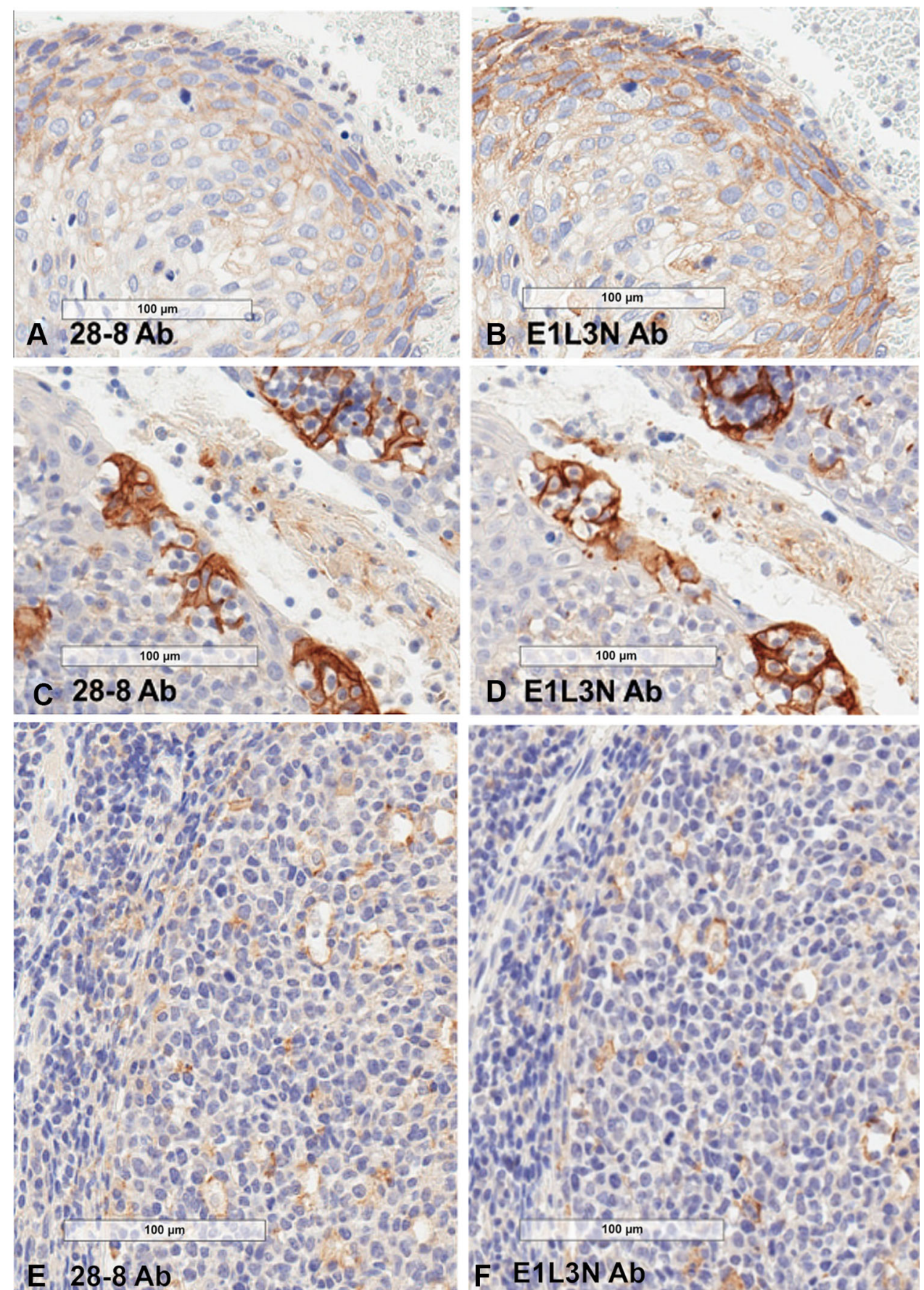

\subsection{Detection Using Manufacturer-Recommended HIER and Detection}

Antibodies 28-8 and E1L3N were compared using manufacturer-recommended methods on a set of 20 NSCLC and 20 melanoma specimens exhibiting a range of PD-L1 expression (Supplemental Table 2). The assays were first compared using a blinded test performed by a single pathologist, with a 1-month washout to discern differences independent of reader bias that may occur between pathologists. Despite using an improved epitope retrieval condition ahead of the E1L3N manufacturer-recommended detection method, we still noted higher sensitivity in staining of PD-L1 using the Dako PD-L1 IHC 28-8 pharmDx retrieval and detection method. The percentage of PD-L1-positive (PD-L1 ${ }^{+}$) tumors (Supplemental Table 2) and immune cell PD-L1 staining frequency (Supplemental Table 3) varied for the set of 20 NSCLC and 20 melanoma specimens. The distribution of the PD$\mathrm{L}^{+}$tumor staining (Fig. $4 \mathrm{a}$, b) and immune cell 


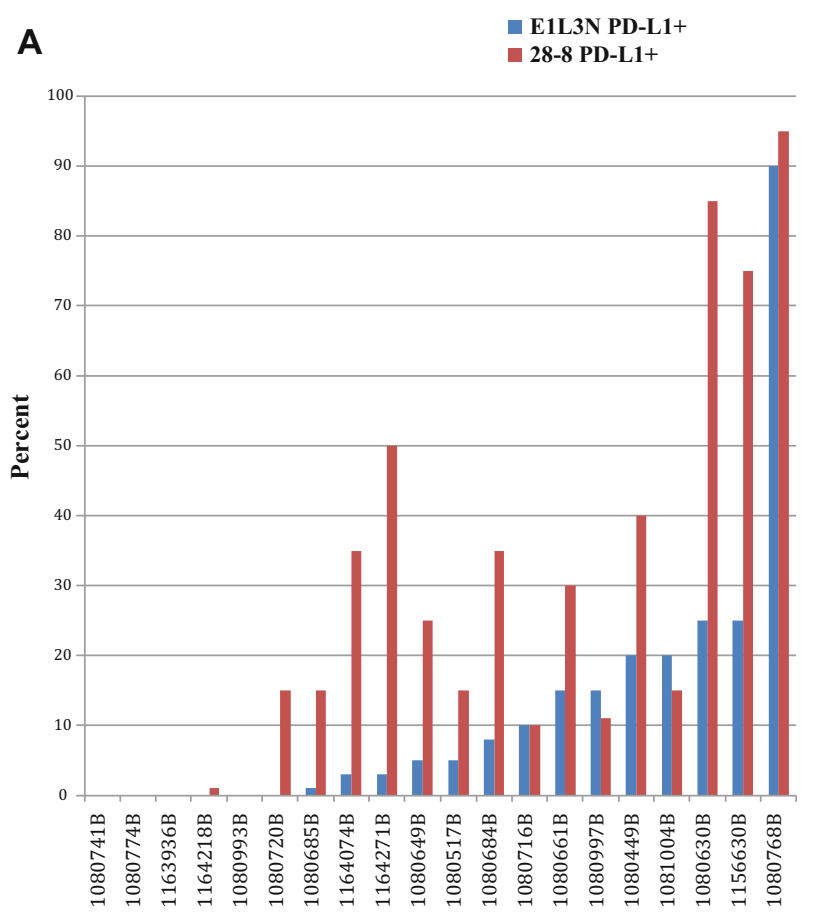

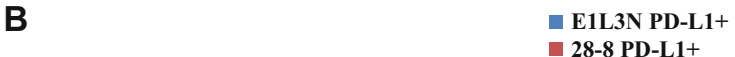

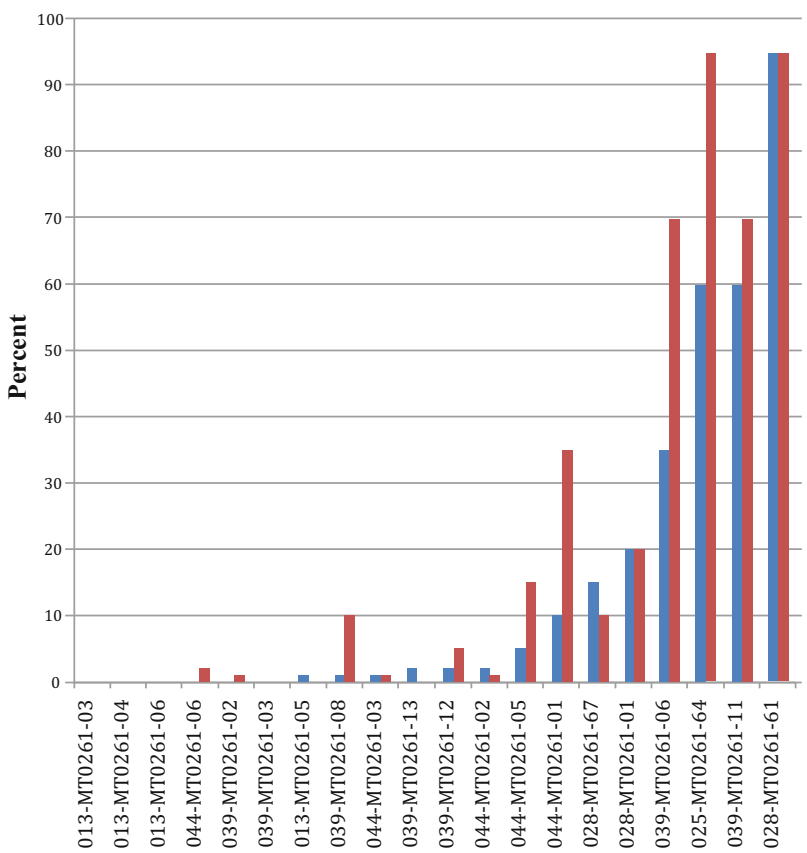

Fig. 4 a Tumor plasma membrane scoring of NSCLC samples. b Tumor plasma membrane scoring of melanoma samples. NSCLC non-smallcell lung cancer, $P D-L 1$ programmed death-ligand

frequencies (Fig. 5a, b) are shown in both tumor types. The percentage of PD- $\mathrm{L}^{+}$tumors detected by the Dako 28-8 assay was in the expected range for both NSCLC [21] and melanoma (publication pending). On matched samples, the PD-L1 IHC 28-8 pharmDx assay more frequently detected PD-L1 ${ }^{+}$tumor (22 vs. 6) and PD-L1 ${ }^{+}$ immune cells (15 vs. 7) compared with the E1L3N CST assay. The average difference across all specimens was higher for the PD-L1 IHC 28-8 pharmDx assay than the E1L3N CST assay for the percentage of PD-L1 ${ }^{+}$tumor staining (20 vs. 3) and $\mathrm{PD}-\mathrm{L}^{+}{ }^{+}$immune cell frequency (1.27 vs. 1; Table 1). In specimens in which the E1L3N CST assay was scored higher for the percentage of PD-L1 tumor, the margin was only 1-5\% greater. Compared with E1L3N, 28-8 scored higher for all parameters in both tumor types except melanomas, in which PD-L1 ${ }^{+}$tumors were detected in equal numbers. Four representative images for NSCLC and melanoma that demonstrate differences in frequency and staining of the plasma membrane between the PD-L1 IHC 28-8 pharmDx assay and the E1L3N CST assay are shown in Supplemental Figures 1-4. In addition, when two independent pathologists reviewed each assay (Table 2 and Supplemental Table 2), the results similarly favored 28-8 Dako pharmDx versus E1L3N CST assay [percentage PD-L1 ${ }^{+}$tumor average difference (18 vs. 7) and number of tumors identified as
$\mathrm{PD}^{-} 1^{+}$(19 vs. 13)], and PD-L1 ${ }^{+}$immune cell density scores (1.24 vs. 1).

\section{Discussion}

Many companies and academic laboratories are developing antibodies to detect PD-L1 as a potential predictive marker for therapies that interfere with the interaction of one or both of the PD-1 ligands with the PD-1 receptor. PD-L1 is expressed on a subset of tumors in many but not all histologies, as well as on immune cells, predominantly the mononuclear leukocytes and monocytes/macrophages that are present in most tumors. IHC assays must be developed that can detect PD-L1 across a large dynamic range and still retain sensitivity for low levels of PD-L1 expression, especially in tumors.

Genetic deletion in cell lines was previously used to demonstrate the specificity of rabbit $\mathrm{mAb} 28-8$, an antibody developed by BMS in collaboration with Abcam and Dako. The present study compares the specificity of 28-8 with E1L3N, a rabbit mAb developed by CST. Both 28-8 and E1L3N are specific for cell surface PD-L1, as evidenced by lack of staining following genetic deletion in L2987 and ES-2 cells. However, the cytoplasm staining of ES-2 knockout cells is significant with E1L3N and negligible 
A

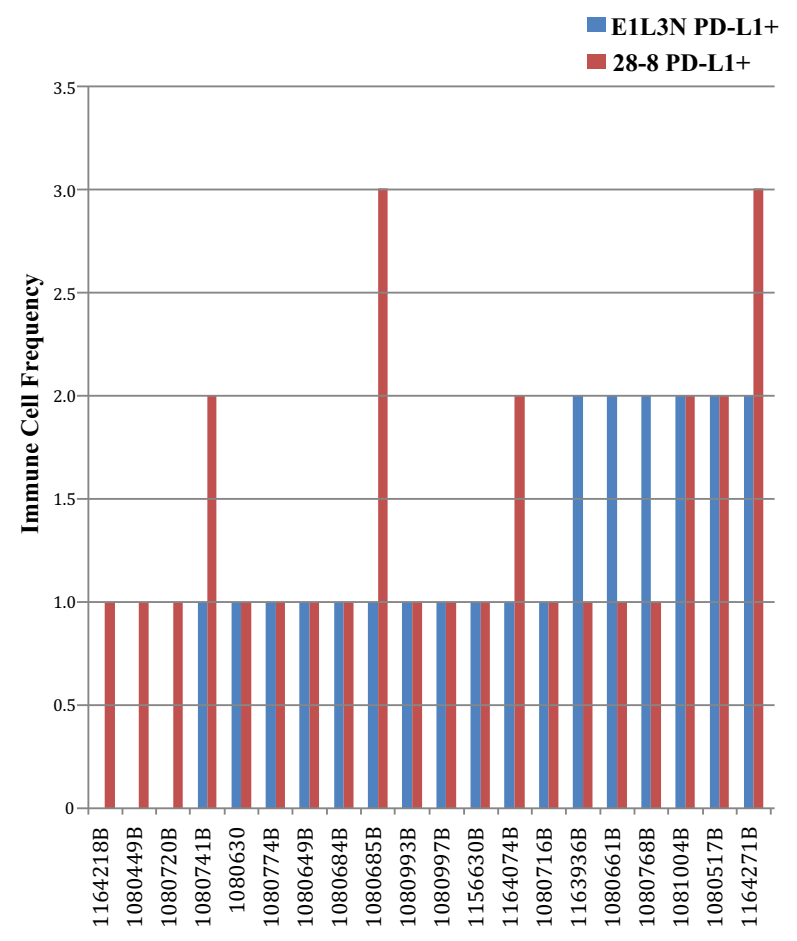

B

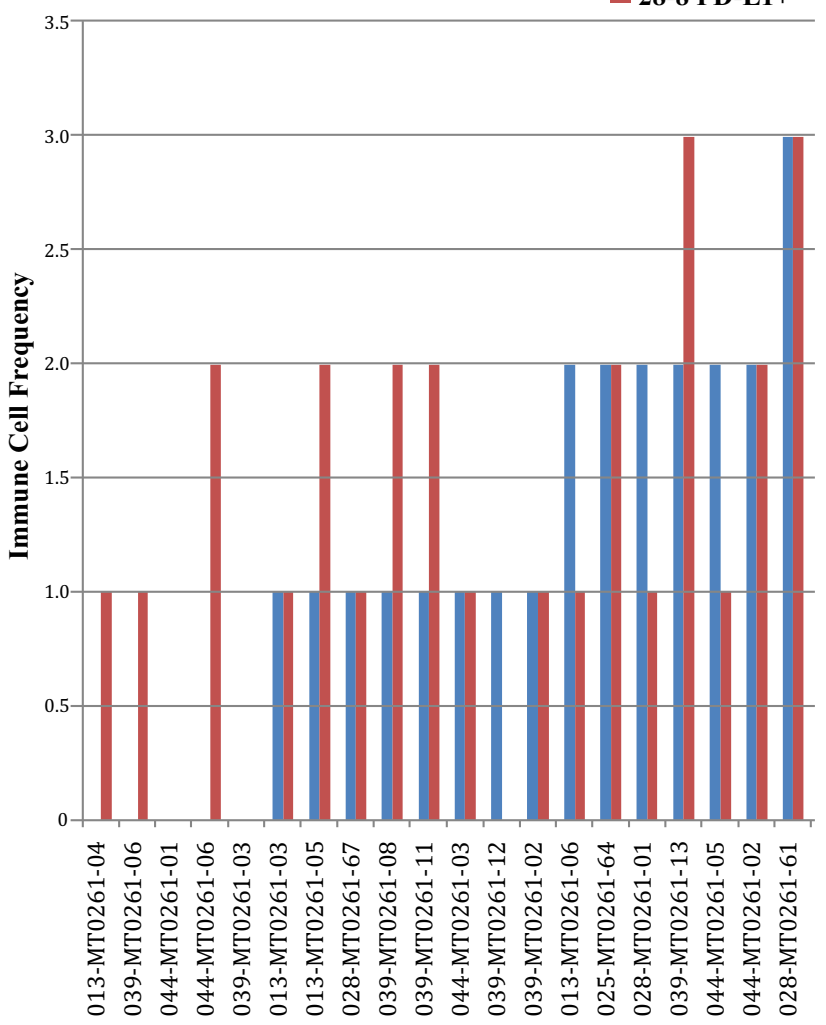

Fig. 5 a Immune cell plasma membrane scoring of NSCLC samples. b Immune cell plasma membrane scoring of melanoma samples. NSCLC non-small-cell lung cancer, $P D-L 1$ programmed death-ligand

Table 1 Single pathologist comparative analysis of the percentage of $\mathrm{PD}-\mathrm{L1}^{+}$tumors and immune scoring

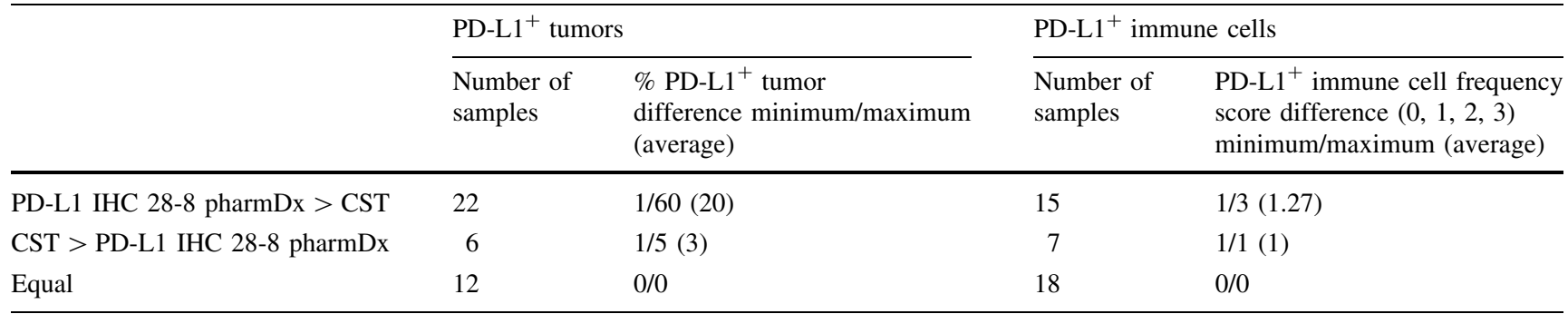

CST cell signaling technology, IHC immunohistochemical, PD-L1 programmed death-ligand 1

with 28-8, suggesting this CST antibody may also recognize a non-PD-L1 protein. Most PD-L1 testing has focused on cell surface staining. Strong cytoplasm staining, when present, can confound assessment of plasma membrane staining. While we cannot directly address whether the remaining cytoplasm staining in ES-2 cells has implications for tissue testing, pathologists were able to detect plasma membrane staining with the E1L3N laboratory developed test (LDT) without interference from cytoplasmic staining.

The intrinsic sensitivity of both antibodies was compared using an identical HIER condition, antibody concentration, and signal detection method. Using this methodology, E1L3N has slightly higher intrinsic sensitivity, as it stains more cells than 28-8 when tested on tonsil (epithelium in crypts, spindloid cells in follicles, and mononuclear leukocytes in follicle and interfollicular areas) and squamous head and neck tumor cells.

We also compared the performance of manufacturerrecommended detection methods provided by Dako and CST. CST recommends SignalStain Detection, whereas Dako has a proprietary linker antibody in their PD-L1 IHC 28-8 pharmDx detection kit. Under these manufacturerrecommended testing protocols, the detection of PD-L1 tumor was higher for 28-8 than for E1L3N, based on 
Table 2 Independent pathologist comparative analysis of the percentage of PD-L1 ${ }^{+}$tumors and immune scoring

\begin{tabular}{|c|c|c|c|c|}
\hline & \multicolumn{2}{|c|}{${\mathrm{PD}-\mathrm{L1}^{+} \text {tumors }}$} & \multicolumn{2}{|c|}{$\mathrm{PD} \mathrm{L1}^{+}$immune cells } \\
\hline & $\begin{array}{l}\text { Number of } \\
\text { samples }\end{array}$ & $\begin{array}{l}\% \text { PD-L1 } 1^{+} \text {tumor difference } \\
\text { minimum/maximum (average) }\end{array}$ & $\begin{array}{l}\text { Number of } \\
\text { samples }\end{array}$ & $\begin{array}{l}\mathrm{PD}-\mathrm{L} 1^{+} \text {immune cell frequency } \\
\text { score difference }(0,1,2,3) \\
\text { minimum/maximum (average) }\end{array}$ \\
\hline PD-L1 IHC 28-8 pharmDx > CST & 19 & $4 / 40(18)$ & 21 & $1 / 2(1.24)$ \\
\hline CST > PD-L1 IHC 28-8 pharmDx & 13 & $1 / 30(7)$ & 1 & $1 / 1(1)$ \\
\hline Equal & 8 & $0 / 0$ & 18 & $0 / 0$ \\
\hline
\end{tabular}

CST cell signaling technology, IHC immunohistochemical, $P D-L 1$ programmed death-ligand 1

number of PD-L1 ${ }^{+}$tumors detected, number of specimens with higher scores, and average increase in the percentage of positive tumors. The detection of PD-L1 tumor was higher for 28-8 versus E1L3N, whether evaluated by a single pathologist in sequence or by two separate pathologists reading each assay independently. The 28-8 antibody was scored higher in melanoma tumor cells for all parameters except PD-L1 ${ }^{+}$tumor frequency. However, pathologists noted that the evaluation of PD-L1 ${ }^{+}$tumors can be challenging in the $1-5 \%$ range when abundant PD$\mathrm{L}^{+}$histiocytes are present. This was more apparent in melanomas for present/absent calls when independent pathologists were reading each assay. Inclusion of stains that identify tumors or histiocytes may aid pathologists in their evaluation process for future studies.

This study was limited by sample size and scope. The size of the tumor sample set used for the comparison of the E1L3N and 28-8 antibodies was small. Larger sample sets (with additional tumor types) are required for a more accurate quantitative comparison, and will allow for other types of analyses such as comparing PD-L1 positivity at specified cutoffs. This study was also limited in scope to the comparison of two PD-L1 antibodies among several that are currently in use for LDT and diagnostic assays. Additional comprehensive analyses of these PD-L1 antibodies are needed, preferably on a common assay platform.

This study demonstrates the advantages of the 28-8 antibody with regard to absolute target specificity and sensitivity using the Dako recommended HIER and detection protocols. Decreased ability to detect cell surface PD-L1 by this CST LDT compared with the Dako pharmDx method has implications for the assessment of PD-L1 expression in patient samples attained for clinical diagnosis. Those laboratories wishing to use LDTs instead of companion diagnostic tests should carefully select the clone and detection method to ensure target specificity and sensitivity. E1L3N should not be used before nivolumab administration as this antibody is not part of a standardized assay/kit that has been analytically and clinically validated (utilized in nivolumab clinical trials) and approved by any regulatory organization. It is important that in vitro predictive and/or prognostic diagnostic assays used to inform clinical treatment decisions are fully validated and meet appropriate standards. Failure to achieve these standards may lead to inaccurate assay results and cause misinterpretation of potential clinical outcomes associated with PD-1 checkpoint inhibitor treatment.

Acknowledgments Jeff Sussman and Martin Bur of New England Pathology Associates are acknowledged for their contributions in evaluating each assay independently. Medical writing and editorial assistance was provided by Mark Semaan and Anne Cooper (StemScientific, NJ, USA) and was funded by Bristol-Myers Squibb.

\section{Compliance with Ethical Standards}

Funding This work and open access publication were supported by funding from Bristol-Myers Squibb.

Conflict of interest John Cogswell, H. David Inzunza, Qiuyan Wu, John Feder, Gabe Mintier, and James Novotny are employees of and stockholders in Bristol-Myers Squibb. Diana Cardona has served in a consulting or advisory role for Bristol-Myers Squibb.

Open Access This article is distributed under the terms of the Creative Commons Attribution-NonCommercial 4.0 International License (http://creativecommons.org/licenses/by-nc/4.0/), which permits any noncommercial use, distribution, and reproduction in any medium, provided you give appropriate credit to the original author(s) and the source, provide a link to the Creative Commons license, and indicate if changes were made.

\section{References}

1. OPDIVO [package insert]. Princeton: Bristol-Myers Squibb Company; 2016.

2. OPDIVO [product information]. Uxbridge: Bristol-Myers Squibb Pharma EEIG; 2015.

3. Dong H, Zhu G, Tamada K, Chen L. B7-H1, a third member of the B7 family, co-stimulates T-cell proliferation and interleukin10 secretion. Nat Med. 1999;5:1365-9.

4. Dong H, Strome SE, Salomao DR, Tamura H, Hirano F, Flies DB, et al. Tumor-associated B7-H1 promotes T-cell apoptosis: a potential mechanism of immune evasion. Nat Med. 2002;8:793-800.

5. Freeman GJ, Long AJ, Iwai Y, Bourque K, Chernova T, Nishimura $\mathrm{H}$, et al. Engagement of the PD-1 immunoinhibitory receptor by a novel $\mathrm{B} 7$ family member leads to negative regulation of lymphocyte activation. J Exp Med. 2000;192:1027-34. 
6. Brown JA, Dorfman DM, Ma FR, Sullivan EL, Munoz O, Wood $\mathrm{CR}$, et al. Blockade of programmed death-1 ligands on dendritic cells enhances $\mathrm{T}$ cell activation and cytokine production. J Immunol. 2003;170:1257-66.

7. Mu C-Y, Huang JA, Chen Y, Chen C, Zhang XG. High expression of PD-L1 in lung cancer may contribute to poor prognosis and tumor cells immune escape through suppressing tumor infiltrating dendritic cells maturation. Med Oncol. 2011;28:682-8.

8. Konishi J, Yamazaki K, Azuma M, Kinoshita I, Dosaka-Akita H, Nishimura M. B7-H1 expression on non-small cell lung cancer cells and its relationship with tumor-infiltrating lymphocytes and their PD-1 expression. Clin Cancer Res. 2004;10:5094-100.

9. Topalian SL, Hodi FS, Brahmer JR, Gettinger SN, Smith DC, McDermott DF, et al. Safety, activity, and immune correlates of anti-PD-1 antibody in cancer. N Engl J Med. 2012;366: 2443-54.

10. Taube JM, Anders RA, Young GD, Xu H, Sharma R, McMiller TL, et al. Colocalization of inflammatory response with B7-H1 expression in human melanocytic lesions supports an adaptive resistance mechanism of immune escape. Sci Transl Med. 2012;4:127ra37.

11. Grosso J, Inzunza D, Wu Q, Simon J, Singh P, Zhang X, et al. Programmed death-ligand 1 (PD-L1) expression in various tumor types. J Immunother Cancer. 2013;1(Suppl 1):P53.

12. Ayers MD, Nebozhyn M, Cristescu R, McClanahan TK, Hirsch HA, Cheng JD, et al. Abstract 256: Identification of additional cancers likely to respond to anti-PD-1 therapy (pembrolizumab): evaluation of PD-L1 expression in a large molecular tumor profiling gene expression database. Cancer Res. 2015;75. doi:10. 1158/1538-7455.AM2015-256.

13. Boland JM, Kwon ED, Harrington SM, Wampfler JA, Tang H, Yang P, et al. Tumor B7-H1 and B7-H3 expression in squamous cell carcinoma of the lung. Clin Lung Cancer. 2013;14:157-63.
14. Gadiot J, Hooijkass AI, Kaiser AD, van Tinteren H, van Boven H, Blank C. Overall survival and PD-L1 expression in metastasized malignant melanoma. Cancer. 2011;117:2192-201.

15. Hino R, Kabashima K, Kato Y, Yagi H, Nakamura M, Honjo T, et al. Tumor cell expression of programmed cell death-1 ligand 1 is a prognostic factor for malignant melanoma. Cancer. 2010;116:1757-66.

16. Taube JM, Klein A, Brahmer JR, Xu H, Pan X, Kim JH, et al. Association of PD-1, PD-1 ligands, and other features of the tumor immune microenvironment with response to anti-PD-1 therapy. Clin Cancer Res. 2014;20:5064-74.

17. Chen YB, Mu CY, Huang JA. Clinical significance of programmed death-1 ligand-1 expression in patients with non-small cell lung cancer: a 5-year-follow-up study. Tumori. 2012;98:751-5.

18. Velcheti V, Schalper KA, Carvajal DE, Anagnostou VK, Syrigos $\mathrm{KN}$, Sznol M, et al. Programmed death ligand-1 expression in non-small cell lung cancer. Lab Invest. 2014;94:107-16.

19. Ohigashi Y, Sho M, Yamada Y, Tsurui Y, Hamada K, Ikeda N, et al. Clinical significance of programmed death-1 ligand-2 expression in human esophageal cancer. Imaging, diagnosis, and prognosis. Clin Cancer Res. 2005;11:2947-53.

20. McLaughlin J, Han G, Schalper KA, Carvajal-Hausdorf D, Pelakanou V, Rehman J, et al. Quantitative assessment of the heterogeneity of PD-L1 expression in non-small cell lung cancer. JAMA Oncol. 2016;2:46-54.

21. Phillips T, Simmons P, Inzunza HD, Cogswell J, Taylor C, Zhang $X$. Development of an automated PD-L1 immunohistochemistry (IHC) assay for non-small cell lung cancer. Appl Immunohistochem Mol Morphol. 2015;23:541-9.

22. Liao Z, Zhu Y, Cai W, Zhang H, Alleman-Sposeto J, Smith S, et al. IHC performance of two rabbit anti-human PD-L1 monoclonal antibodies. Pleasanton: Spring Bioscience; 2014. http://products. springbio.com/doc.ashx?docid=5800. Accessed 4 Aug 2016. 